\title{
Decoction, infusion and hydroalcoholic extract of cultivated thyme: Antioxidant and antibacterial activities, and phenolic characterisation
}

\author{
Natália Martins $^{\mathrm{a}, \mathrm{b}}$, Lillian Barros ${ }^{\mathrm{a}, *}$, Celestino Santos-Buelga ${ }^{\mathrm{c}}$, Sónia Silva ${ }^{\mathrm{b}}$, Mariana Henriques ${ }^{\mathrm{b}}$, \\ Isabel C.F.R. Ferreira ${ }^{\mathrm{a}, *}$ \\ ${ }^{a}$ Mountain Research Centre (CIMO), ESA, Polytechnic Institute of Bragança, Campus de Santa Apolónia, Apartado 1172, $5301-855$ Bragança, Portugal \\ ${ }^{\mathrm{b}} \mathrm{CEB}$, Centre of Biological Engineering, University of Minho, 4710-057 Braga, Portugal

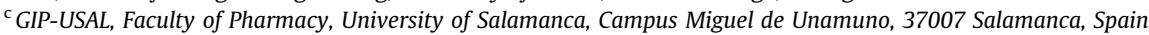

\section{A R T I C L E I N F O}

\section{Article history:}

Received 23 February 2014

Received in revised form 4 June 2014

Accepted 24 June 2014

Available online 2 July 2014

\section{Keywords:}

Thymus vulgaris $\mathrm{L}$.

Decoction/infusion

Hydroalcoholic extract

Phenolic compounds

Antioxidant/antibacterial activity

\begin{abstract}
A B S T R A C T
Bioactivity of thyme has been described, but mostly related to its essential oils, while studies with aqueous extracts are scarce. Herein, the antioxidant and antibacterial properties of decoction, infusion and hydroalcoholic extract, as also their phenolic compounds, were evaluated and compared. Decoction showed the highest concentration of phenolic compounds (either phenolic acids or flavonoids), followed by infusion and hydroalcoholic extract. In general, the samples were effective against gram-positive (Staphylococcus aureus and Staphylococcus epidermidis) and gram-negative (Escherichia coli, Klebsiella spp., Pseudomonas aeruginosa, Enterococcus aerogenes, Proteus vulgaris and Enterobacter sakazakii) bacteria, with decoction presenting the most pronounced effect. This sample also displayed the highest radical scavenging activity and reducing power. Data obtained support the idea that compounds with strong antioxidant and antibacterial activities are also water-soluble. Furthermore, the use of thyme infusion and decoction, by both internal and external use, at recommended doses, is safe and no adverse reactions have been described.
\end{abstract}

(c) 2014 Elsevier Ltd. All rights reserved.

\section{Introduction}

Continuous exposure to various sources of aggressors leads to an increase in the production of reactive species, cellular deterioration and, in long term, contributes to aging and other organic disorders. Oxygen, nitrogen and sulphur reactive species, including free radicals, have been implicated in the onset of various diseases such as neurodegenerative diseases, cancer, cardiovascular diseases, cataracts, rheumatism, ulcers, and atherosclerosis. Antioxidants have the ability to neutralize these species, protecting cell's molecules namely, proteins, lipids, carbohydrates and nucleic acids (Carocho \& Ferreira, 2013; Chaturvedi \& Beal, 2013; Rubió, Motilva, \& Romero, 2013). Furthermore, since the middle of twentieth century, a continuous and significant increase in the incidence and prevalence of opportunistic infections has been observed, not only in immunocompromised and hospitalised patients, but also in the general population. The indiscriminate and disseminate use of antimicrobial agents has contributed to an increase of microbiological resistance (Kon \& Rai, 2012; Van Vuuren, Suliman, \& Viljoen, 2009).

\footnotetext{
* Corresponding authors. Tel.: +351273 303219; fax: +351273 325405. E-mail addresses: lillian@ipb.pt (L. Barros), iferreira@ipb.pt (I.C.F.R. Ferreira).
}

The use of medicinal plants for prevention or treatment of various conditions is an old tradition, but recently, has sparked an increasing interest by researchers that have been studying their biological properties (Rubió et al., 2013; Silva \& Fernandes Júnior, 2010). In fact, natural matrices can give an exogenous contribution to the detoxification and elimination of reactive species (Carocho \& Ferreira, 2013) and also to the discovery of novel antimicrobial compounds (Maroyi, 2013).

Thymus vulgaris L., commonly known as thyme, could be one of those matrices, providing a wide range of biomolecules, such as phenolic compounds. Thyme is a perennial subshrub widely cultivated around the world and belongs to the Lamiaceae (lipped) family. It is used, since ancient times, both for nutritional and medicinal purposes. Commonly known by its multiple health benefits, thyme infusions, decoctions or essential oils are mostly used due to antispasmodic activity in smooth muscle (bronchial and intestinal), immunostimulant, expectorant, mucolytic, antitussive/bronchodilator, and digestive/eupeptic properties (Vanaclocha \& Cañigueral, 2003). Some studies have also reported its antioxidant (Kulisic, Radonic, \& Milos, 2005; Viuda-Martos, Navajas, Zapata, Fernández-López, \& Pérez-Álvarez, 2010) and antimicrobial (Imelouane et al., 2009; Kon \& Rai, 2012) properties, but mostly referring to its essential oils, whereas only a few studies 
report the bioactivities of aqueous extracts, namely decoctions or infusions (Kulisic, Dragovi-Uzelac, \& Milos, 2006; Roby, Sarhan, Selim, \& Khalel, 2013). Regarding chemical composition, the majority of the studies also refer to essential oils (e.g., Giordani et al., 2004; Imelouane et al., 2009; Kulisic et al., 2005; Viuda-Martos, Ruíz-Navajas, Fernández-López, \& Pérez-Álvarez, 2007), while less work has been done in relation to its phenolic composition (Boros et al., 2010; Dapkevicius et al., 2002; Koşar, Dorman, \& Hiltunen, 2005; Miron, Plaza, Bahrim, Ibáñez, \& Herrero, 2011; Nagy, Solar, Sontag, \& Koenig, 2011; Roby et al., 2013; Vergara-Salinas, PérezJiménez, Torres, Agosin, \& Pérez-Correa, 2012). The main phenolic compounds identified in the studied thyme samples were rosmarinic acid, caffeic and ferulic acids and their derivatives. Furthermore, Kulisic, Dragovi-Uzelac and Milos (2006) studied the antioxidant activity of thyme infusions as related to the phenolic composition, but as far as we know no reports are available in decoctions.

In the present work, the antioxidant and antibacterial properties of decoction, infusion and hydroalcoholic extracts of thyme (T. vulgaris L.) were evaluated, compared and characterised in terms of their composition of phenolic compounds.

\section{Materials and methods}

\subsection{Sample}

Flowering aerial parts (leaves and flowers, separated from branches) of $T$. vulgaris L., previously dried, supplied by Soria Natural (Garray - Soria, Spain), were obtained in September 2012. The sample was a clean product, with monitored parameters of pesticides, herbicides, heavy metals and radioactivity.

\subsection{Standards and reagents}

Methanol was of analytical grade and supplied by Pronalab (Lisbon, Portugal). 2,2-Diphenyl-1-picrylhydrazyl (DPPH) was obtained from Alfa Aesar (Ward Hill, MA, USA). HPLC-grade acetonitrile was obtained from Merck KgaA (Darmstadt, Germany). Formic acids was purchased from Prolabo (VWR International, Fontenay-sous-Bois, France). Phenolic standards (apigenin 6-Cglucoside, caffeic acid, chlorogenic acid, 3,4-dihydroxyphenylacetic acid, eriodictyol, hesperitin, isorhamnetin 3-O-rutinoside, kaempferol 3-O-glucoside, luteolin 7-O-glucoside, myricetin, protocatechuic acid, quercetin-3-O-glucoside, quercetin-3-O-rutinoside, rosmarinic acid) were from Extrasynthese (Genay, France). Trolox (6-hydroxy-2, 5,7,8-tetramethylchroman-2-carboxylic acid) was purchased from Sigma Chemical Co. (St. Louis, MO, USA). Water was treated in a Milli-Q water purification system (TGI Pure Water Systems, Greenville, SC, USA).

\subsection{Preparation of the hydroalcoholic extract, infusion and decoction}

Hydroalcoholic extractions were performed by stirring the plant material ( $1 \mathrm{~g})$ with $30 \mathrm{~mL}$ of methanol/water $(80: 20, v / v)$ at $25^{\circ} \mathrm{C}$ and $150 \mathrm{rpm}$ for $1 \mathrm{~h}$ and filtered through Whatman No. 4 paper. The residue was then extracted with one additional $30 \mathrm{~mL}$ portion of the hydroalcoholic mixture. The combined extracts were evaporated at $35{ }^{\circ} \mathrm{C}$ under reduced pressure (rotary evaporator Büchi R-210, Flawil, Switzerland) and then further lyophilized (FreeZone 4.5, Labconco, Kansas City, MO, USA).

Infusions were prepared by adding $200 \mathrm{~mL}$ of boiling distilled water to the sample $(1 \mathrm{~g})$ and were left to stand at room temperature for $5 \mathrm{~min}$, and then filtered under reduced pressure. Decoctions were performed by adding to $200 \mathrm{~mL}$ of distilled water to the sample $(1 \mathrm{~g})$, heated (heating plate, VELP scientific) and boiled for $5 \mathrm{~min}$. The mixtures were left to stand for $5 \mathrm{~min}$ and then filtered under reduced pressure. The infusions and decoctions were frozen and lyophilized. The lyophilized hydroalcoholic extract, infusion and decoction were re-dissolved in methanol/water $(80: 20, v / v)$ and water, respectively, to obtain a stock solution of $20 \mathrm{mg} / \mathrm{mL}$.

\subsection{Evaluation of antioxidant activity}

Four different in vitro assays were performed using solutions prepared by serial dilution of stock solution: scavenging effects on DPPH (2,2-diphenyl-1-picrylhydrazyl) radicals, reducing power (measured by ferricyanide Prussian blue assay), inhibition of $\beta$-carotene bleaching and inhibition of lipid peroxidation in brain cell homogenates by TBARS (thiobarbituric acid reactive substances) assay.

DPPH radical-scavenging activity was evaluated by using a ELX800 microplate Reader (Bio-Tek Instruments, Inc; Winooski, VT, USA), and calculated as a percentage of DPPH discolouration using the formula: $\left[\left(A_{D P P H}-A_{S}\right) / A_{D P P H}\right] \times 100$, where $A_{S}$ is the absorbance of the solution containing the sample at $515 \mathrm{~nm}$, and $A_{D P P H}$ is the absorbance of the DPPH solution (Chahdoura et al., 2014). Reducing power was evaluated by the capacity to convert $\mathrm{Fe}^{3+}$ into $\mathrm{Fe}^{2+}$, measuring the absorbance at $690 \mathrm{~nm}$ in the microplate Reader mentioned above. Inhibition of $\beta$-carotene bleaching was evaluated though the $\beta$-carotene/linoleate assay; the neutralization of linoleate free radicals avoids $\beta$-carotene bleaching, which is measured by the formula: $\beta$-carotene absorbance after $2 \mathrm{~h}$ of assay/initial absorbance) $\times 100$ (Chahdoura et al., 2014). Lipid peroxidation inhibition in pig (Sus scrofa) brain homogenates was evaluated by the decreasing in thiobarbituric acid reactive substances (TBARS); the colour intensity of the malondialdehyde-thiobarbituric acid (MDA-TBA) abduct was measured by its absorbance at $532 \mathrm{~nm}$; the inhibition ratio (\%) was calculated using the following formula: $[(A-B) / A] \times 100 \%$, where $A$ and $B$ were the absorbance of the control and the sample solution, respectively. The results were expressed in $\mathrm{EC}_{50}$ values $(\mu \mathrm{g} / \mathrm{mL})$, i.e. sample concentration providing $50 \%$ of antioxidant activity or 0.5 of absorbance in the reducing power (Chahdoura et al., 2014).

\subsection{Evaluation of antibacterial activity}

To evaluate antibacterial activity, different bacteria were used (provided from American Type Culture Collection - ATCC), namely Gram positive species, such as, Staphylococcus aureus (ATCC 25923) and Staphylococcus epidermidis (ATCC 35983), and Gram negative species, as Escherichia coli (ATCC 25922), Klebsiella spp., Pseudomonas aeruginosa (ATCC 10145), Enterococcus aerogenes (ATCC 2048), Proteus vulgaris (ATCC 6380) and Enterobacter sakazakii (ATCC 29544). The antibacterial effect was evaluated using the disc diffusion halo test (NCCLS/CLSI \& ANVISA, 2003). For that, each species was cultivated in a liquid medium, containing $30 \mathrm{~mL}$ of Tryptic Soy Broth (TSB), during $24 \mathrm{~h}$. After that, the concentration of each species was normalised for an optic density of 0.5 (corresponding approximately to $1 \times 10^{7}$ cells $/ \mathrm{mL}$ ) by absorbance determination at $600 \mathrm{~nm}$. An aliquot of each species $(300 \mu \mathrm{L})$ was spread in Tryptic Soy Agar (TSA) petri dishes. Then, an aliquot of $25 \mu \mathrm{L}$ of each sample (decoction, infusion and hydroalcoholic extract dissolved in water $-20 \mathrm{mg} / \mathrm{mL}$ ) was placed on sterile blank disc. The plates were incubated at $37^{\circ} \mathrm{C}$, during $24-48 \mathrm{~h}$. Antibacterial activity was measured using a qualitative method, based on disc diffusion assay. The qualitative results were converted in a semi-quantitative scale being classified the distinctness of the halo as: $(-)$ absence of halo; (+) weak halo; (++) moderate halo; (+++) strong halo. Absence of halo concerning to $0.0 \mathrm{~mm}$; weak halo between 3.0 and $7.0 \mathrm{~mm}$; moderate halo $8.0-10.0 \mathrm{~mm}$, and strong halo greater than $11.0 \mathrm{~mm}$. 


\subsection{Analysis of phenolic compounds}

Phenolic compounds were determined by HPLC (Hewlett-Packard 1100, Agilent Technologies, Santa Clara, CA, USA) as previously described (Barros et al., 2013). A Waters Spherisorb S3 ODS-2 $C_{18}$, $3 \mu \mathrm{m}(4.6 \mathrm{~mm} \times 150 \mathrm{~mm})$ column thermostatted at $35^{\circ} \mathrm{C}$ was used. The injection volume was $100 \mu \mathrm{L}$. The solvents used were: (A) $0.1 \%$ formic acid in water, (B) acetonitrile. The elution gradient established was isocratic $15 \%$ for $5 \mathrm{~min}, 15 \%$ B to $20 \%$ B over $5 \mathrm{~min}, 20-25 \%$ B over $10 \mathrm{~min}, 25-35 \%$ B over $10 \mathrm{~min}, 35-50 \%$ for $10 \mathrm{~min}$, and re-equilibration of the column, using a flow rate of $0.5 \mathrm{~mL} / \mathrm{min}$. Double online detection was carried out using diode array detector (DAD) using 280 at $370 \mathrm{~nm}$ as preferred wavelengths and a mass spectrometer (MS) connected to the HPLC system via the DAD cell outlet. The phenolic compounds were identified by comparing their retention time, UV-vis and mass spectra with those obtained from standard solutions, when available. Otherwise, peaks were tentatively identified comparing the obtained information with available data reported in the literature. For quantitative analysis, a calibration curve (1-100 $\mu \mathrm{g} / \mathrm{mL})$ for each available phenolic standard was constructed based on the UV signal: apigenin 6-C-glucoside $(y=223.22 x+60.915$ $\left.R^{2}=1\right)$; caffeic acid $\left(y=611.9 x-4.5733 ; R^{2}=0.999\right)$; chlorogenic acid $\left(y=313.03 x-58.2 ; \quad R^{2}=0.999\right) ; \quad$ eriodictyol $\quad(y=517.4 x+$ 268.26; $\left.R^{2}=0.992\right)$; hesperitin $\left(y=178.59 x+154.29 ; R^{2}=0.999\right)$; isorhamnetin 3-O-rutinoside $\left(y=327.42 x+313.78 ; R^{2}=0.999\right)$; kaempferol 3-O-glucoside ( $\left.y=288.55 x-4.0503 ; R^{2}=1\right)$; kaempferol 3-O-rutinoside ( $\left.y=239.16 x-10.587 ; R^{2}=1\right)$; luteolin 7-O-glucoside $\left(y=80.829 x-21.291 ; R^{2}=0.999\right) ;$ protocatechuic acid $(y=291.1 x$ $\left.-6.4558 ; \quad R^{2}=0.999\right) ;$ quercetin-3-O-glucoside $(y=363.45 x+$ 117.86; $\left.\quad R^{2}=0.999\right)$, quercetin-3-O-rutinoside $(y=281.98 x-$ $\left.0.3459 ; R^{2}=1\right)$; rosmarinic acid $\left(y=336.03 x+170.39 ; R^{2}=0.999\right)$ For the identified phenolic compounds for which a commercial standard was not available, the quantification was performed through the calibration curve of other compounds from the same phenolic group. The results were expressed in mg per $\mathrm{g}$ of extract (the extraction yields to allow conversion for starting material are provided in Table 1 ).

\subsection{Statistical analysis}

All samples of thyme (infusion, decoction and hydroalcoholic extract) were prepared and analyzed in triplicate. The results, expressed as mean values and standard deviation (SD), were analyzed using one-way analysis of variance (ANOVA) followed by Turkey's HSD Test with $\alpha=0.05$, performed with SPSS v. 22.0 program.

\section{Results and discussion}

\subsection{Evaluation of antioxidant activity}

Table 1 shows the results obtained for antioxidant activity. In general, all the preparations revealed antioxidant potential, namely reducing power (RP), free radical scavenging activity (RSA), $\beta$-carotene bleaching inhibition (CBI) and lipid peroxidation
Table 2

Antibacterial activity of infusion, decoction and hydroalcoholic extract of Thymus vulgaris $\mathrm{L}$. (mean $\pm \mathrm{SD}$ )

\begin{tabular}{llll}
\hline & Infusion & Decoction & Hydroalcoholic extract \\
\hline Gram positive bacteria & & & \\
Staphylococcus aureus & - & - & - \\
Staphylococcus epidermidis & ++ & ++ & + \\
Gram negative bacteria & & & \\
Escherichia coli & ++ & +++ & ++ \\
Klebsiella spp. & - & - & - \\
Pseudomonas aeruginosa & + & ++ & + \\
Enterobacter aerogenes & + & + & + \\
Enterobacter sakazakii & + & + & + \\
Proteus vulgaris & + & ++ & ++ \\
\hline
\end{tabular}

(-) Absence of halo; (+) weak halo; (++) moderate halo; (+++) stronger halo.

inhibition (LPI) in brain cell homogenates. Decoction preparation

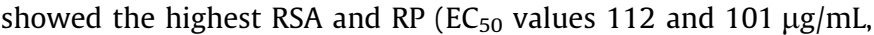
respectively), while infusion revealed the highest LPI $(7 \mu \mathrm{g} / \mathrm{mL})$. Concerning $\mathrm{CBI}$, it was the hydroalcoholic extract that showed the highest value $(32 \mu \mathrm{g} / \mathrm{mL})$.

These results are in agreement with those of Roby et al. (2013) using methanol, ethanol, diethyl ether and hexane extracts of thyme from Egypt that related higher antioxidant capacity with higher contents in polyphenols, as obtained by using higher polarity solvents. Thus, in that study, the highest RSA was reported for the hydroalcoholic extract. The same correlation between higher contents in polyphenol compounds and antioxidant activity (measured by RSA, CBI and LPI assays) was also reported by Kulisic et al. (2006) who studied the infusions of cultivated and wild thyme from Croatia. Nevertheless, the results of RSA reported by those authors were not as good (with higher $\mathrm{EC}_{50}$ values $300 \mu \mathrm{g} / \mathrm{mL}$, for cultivated thyme and $450 \mu \mathrm{g} / \mathrm{mL}$, for wild thyme) compared to the ones obtained in the present study $(126.3 \mu \mathrm{g} / \mathrm{mL})$.

\subsection{Evaluation of antibacterial activity}

(Table 2) shows the results obtained in the screening of antibacterial activity of the infusion, decoction and hydroalcoholic extract prepared from thyme. Regarding Gram positive bacteria, although $S$. aureus and $S$. epidermidis belong to the same genus, thyme preparations only presented activity against $S$. epidermidis. The most pronounced effect was observed for Gram negative bacteria, with the order $E$. coli $>P$. vulgaris, $P$. aeruginosa $>E$. aerogenes $=$ E. sakazakii. No effects were observed against Klebsiella spp. For Gram positive bacteria, decoction and infusion showed similar antibacterial activity, while hydroalcoholic extract revealed a lower activity. Regarding Gram negative bacteria, in general, decoction and hydroalcoholic extract had similar effect, except against $P$. aeruginosa, where infusion showed the lowest activity.

The majority of the studies available in the literature report antimicrobial activity of thyme essential oils, either individually (Abdul, Hassan, \& Hassan, 2012; Oussalah, Caillet, Saucier, \& Lacroix, 2007) or combined with other essential oils (Al-Bayati,

Table 1

Extraction yield (\%) and antioxidant activity $\left(\mathrm{EC}_{50}\right.$ values, $\mu \mathrm{g} / \mathrm{mL}$ ) of infusion, decoction and hydroalcoholic extract of Thymus vulgaris $\mathrm{L}$. (mean $\pm \mathrm{SD}$ ).

\begin{tabular}{|c|c|c|c|}
\hline & Infusion & Decoction & Hydroalcoholic extract \\
\hline Extraction yield & $12.11 \pm 1.62$ & $10.96 \pm 2.18$ & $6.98 \pm 0.31$ \\
\hline DPPH scavenging activity (RSA) & $126.3 \pm 3.9^{b}$ & $112.3 \pm 5.4^{\mathrm{c}}$ & $279.2 \pm 1.8^{\mathrm{a}}$ \\
\hline Reducing power (RP) & $116.8 \pm 2.2^{\mathrm{b}}$ & $100.7 \pm 2.4^{c}$ & $183.0 \pm 3.9^{\mathrm{a}}$ \\
\hline$\beta$-Carotene bleaching inhibition (CBI) & $86.4 \pm 7.9^{b}$ & $207.9 \pm 6.1^{\mathrm{a}}$ & $31.6 \pm 0.8^{c}$ \\
\hline TBARS inhibition (LPI) & $7.1 \pm 0.3^{c}$ & $14.1 \pm 0.6^{\mathrm{a}}$ & $12.9 \pm 0.2^{\mathrm{b}}$ \\
\hline
\end{tabular}

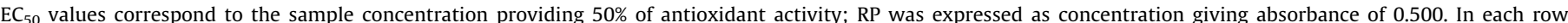
different letters mean significant differences $(p<0.05)$. 
2008; Kon \& Rai, 2012) or conventional antimicrobial agents. (Van Vuuren et al., 2009). A few experiments have reported the use of extracts. Carretto et al. (2007) described the interference of an aqueous extract of thyme on the adherence of Streptococcus mutans and Candida albicans to acrylic resin, and only verified a significant reduction of adherence in $C$. albicans, while there were no positive results for S. mutans. Moreover, Dababneh (2007) reported antimicrobial activity of thyme ethanolic extracts against six pathogens (S. aureus, P. aeruginosa, E. coli, Enterobacter sp. and C. albicans). Nevertheless, the extract concentrations were higher $(100,200$, $400,600,800$ and $1000 \mathrm{mg} / \mathrm{mL}$ ) than the ones tested in the present work $(20 \mathrm{mg} / \mathrm{mL})$.

\subsection{Identification and quantification of phenolic compounds}

The phenolic profile of $T$. vulgaris, obtained after hydroalcoholic extraction, and recorded at $370 \mathrm{~nm}$ is shown in Fig. 1; peak characteristics and tentative identities are presented in Table 3. Twentyfour compounds were detected, seven of which were phenolic acid derivatives and seventeen flavonoids. As for the phenolic acids, 3,4dihydroxyphenylacetic acid (peak 1), protocatechuic acid (peak 2), 5-O-caffeoylquinic acid (peak 3), caffeic acid (peak 5) and rosmarinic acid (peak 18) were positively identified according to their retention, mass and UV-vis characteristics by comparison with commercial standards. Peak $11\left([\mathrm{M}-\mathrm{H}]^{-}\right.$at $m / z$ 521) was identified as rosmarinic acid-glucoside, compound previously reported to occur in thyme (Nagy et al., 2011). Peak 22 ([M-H $]^{-}$at $m / z$ 537), consistent with the caffeic acid trimers salvianolic acids $\mathrm{H} / \mathrm{I}$ and lithospermic acid A. Salvianolic acid I (i.e., 3'-O-( $8^{\prime \prime}-Z$-caffeoyl)rosmarinic acid) was identified in $T$. vulgaris leaves by Dapkevicius et al. (2002) and further reported in dried thyme by Nagy et al. (2011). However, the fragmentation pattern of peak 22 matched better with the one described for lithospermic acid A than for salvianolic acid I by Zeng, Xiao, Liu, and Liang (2006) and Ruan, Li, Li, Luo, and Kong (2012). Therefore, the compound was tentatively assigned to be lithospermic acid.

Flavonoids detected in the analysed sample belonged to the groups of flavones, flavonols and flavanones. Quercetin 3-O-rutinoside (peak 12), quercetin 3-O-glucoside (peak 13), luteolin 7-O-glucoside (peak 15) and eriodictyol (peak 23) were positively identified according to their retention, mass and UV-vis characteristics by comparison with commercial standards.

Quercetin 3-O-glucoside was previously reported in $T$. vulgaris (Vergara-Salinas et al., 2012), whereas luteolin 7-O-glucoside was identified in thyme infusions (Kulisic et al., 2006), leaves from T. vulgaris (Hossain et al., 2010; Vergara-Salinas et al., 2012) and wild thyme (Thymus serpyllum) (Miron et al., 2011). The presence of eriodictyol in different Thymus species was reported by Kosar et al. (2005), Boros et al. (2010) and Miron et al. (2011), and rutin (i.e., quercetin 3-O-rutinoside) was also previously reported by Boros et al. (2010) and Hossain, Rai, Brunton, Martin-Diana, and Barry-ryan (2010).

Peaks 6 and $9\left([\mathrm{M}-\mathrm{H}]^{-}\right.$at $m / z$ 449) were consistent with eriodictyol $O$-hexoside, although the nature and position of the sugar residue could not be established. An eriodictyol-glucoside was also found in thyme by Nagy et al. (2011). Peaks 7, 10 and 14 were identified as luteolin derivatives according to their UV and mass spectral characteristics. Peak $14\left([\mathrm{M}-\mathrm{H}]^{-}\right.$at $m / z$ 461) was assigned to luteolin 7-O-glucuronide, owing to the identification of that compound in leaves from T. vulgaris by Dapkevicius et al. (2002) and Vergara-Salinas et al. (2012), and wild thyme (T. serpyllum) by Miron et al. (2011). Peak $7\left([\mathrm{M}-\mathrm{H}]^{-}\right.$at $\mathrm{m} / z$ 637) was tentatively identified as luteolin $O$-diglucuronide and peak $10\left([\mathrm{M}-\mathrm{H}]^{-}\right.$at $\mathrm{m} / \mathrm{z}$ 447) was assigned to a luteolin hexoside. Peak $8\left([\mathrm{M}-\mathrm{H}]^{-}\right.$at $\mathrm{m} / \mathrm{z}$ 463) was assigned as quercetin $O$-hexoside and the presence of quercetin 7-O-glucoside in thyme was cited by Roby et al. (2013), which might correspond to peak 8 in our sample. Peak 17 showed the same mass spectral characteristics as peak 12 but a different UV spectrum with $\lambda_{\max }$ at $284 \mathrm{~nm}$ consistent with a flavanone, which allowed its assignment as a hesperetin $O$-rutinoside. Vallverdú-Queralt et al. (2014) revealed the presence of hesperetin 7-O-rutinoside, which could correspond to this peak. The presence of hesperetin as an aglycone in different Thymus species has also been cited by Boros et al. (2010).

Peak $16\left([\mathrm{M}-\mathrm{H}]^{-}\right.$at $\left.m / z 477\right)$ presented characteristic UV and MS spectra consistent with an isorhamnetin hexoside. An undefined isorhamnetin 3-O-hexoside was also reported in thyme by Hossain et al. (2010). Peak $19\left([\mathrm{M}-\mathrm{H}]^{-}\right.$at $\left.m / z 445\right)$ was tentatively assigned as apigenin $\mathrm{O}$-glucuronide. Apigenin 7-O-glucuronide was reported in wild thyme by Miron et al. (2011), and an undefined apigenin-glucuronide was also found in dried thyme spices by Nagy et al. (2011). Similarly, peak $21\left([\mathrm{M}-\mathrm{H}]^{-}\right.$at $m / z 477$, and $\mathrm{MS}^{2}$ fragment ion at $\mathrm{m} / \mathrm{z} 285$ ) could be assigned as kaempferol $O$-glucuronide. Peak $20\left([\mathrm{M}-\mathrm{H}]^{-}\right.$at $\left.m / z 607\right)$ yielded fragment ions at $\mathrm{m} / z 299$ ( $-308 \mathrm{mu}$; loss of a rhamosyl glucoside residue) and 284 (further loss of $-\mathrm{CH}_{3}$ ), which allowed its assignment as methyl kaempferol $O$-rutinoside. As far as we know, methyl kaempferol derivatives have not been previously reported in thyme. Peak 24 $\left([\mathrm{M}-\mathrm{H}]^{-}\right.$at $\left.m / z 283\right)$ could correspond to a methyl apigenin, as it was reported in thyme by Hossain et al. (2010). Finally, peak 4 $\left([\mathrm{M}-\mathrm{H}]^{-}\right.$at $m / z$ 593) was identified as apigenin-6,8-di-C-glucoside previously reported in thyme by Vergara-Salinas et al. (2012).

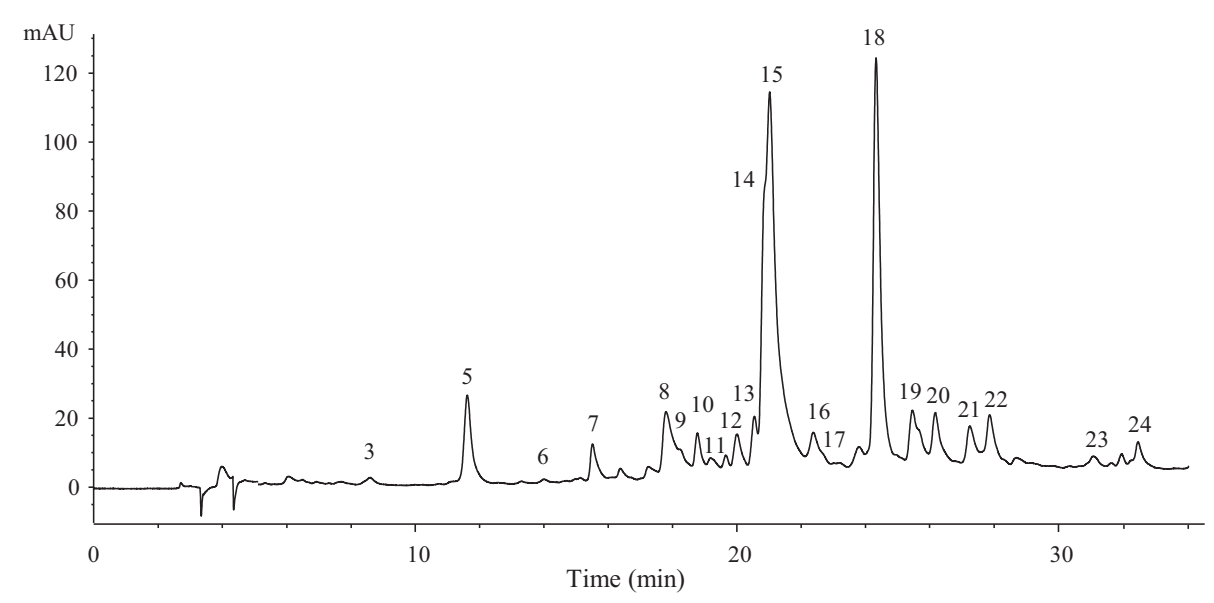

Fig. 1. Phenolic profile of Thymus vulgaris hydroalcoholic extract recorded at $370 \mathrm{~nm}$. 
Table 3

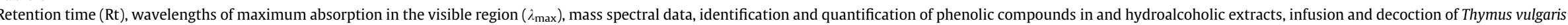
L. (mean $\pm S D)$.

\begin{tabular}{|c|c|c|c|c|c|c|c|c|}
\hline \multirow[t]{2}{*}{ Peak } & \multirow[t]{2}{*}{$\operatorname{Rt}(\min )$} & \multirow[t]{2}{*}{$\lambda_{\max }(\mathrm{nm})$} & \multirow{2}{*}{$\begin{array}{l}\text { Molecular ion } \\
{[\mathrm{M}-\mathrm{H}]^{-}(\mathrm{m} / \mathrm{z})}\end{array}$} & \multirow[t]{2}{*}{$\mathrm{MS}^{2}(m / z)$} & \multirow[t]{2}{*}{ Identification } & \multicolumn{3}{|c|}{ Quantification (mg/g extract) } \\
\hline & & & & & & Infusion & Decoction & Hydroalcoholic \\
\hline 1 & 4.85 & 280 & 197 & 179(38), 151(9), 135(100) & 3,4-Dihydroxyphenylacetic acid & $1.72 \pm 0.09$ & $1.90 \pm 0.16$ & $1.57 \pm 0.02$ \\
\hline 2 & 6.22 & $258, \operatorname{sh} 292$ & 153 & $123(2), 109(100)$ & Protocatechuic acid & $0.73 \pm 0.01$ & $0.85 \pm 0.04$ & $0.76 \pm 0.02$ \\
\hline 3 & 8.38 & 330 & 353 & 191(100), 179(5), 173(4), 161(4), 135(2) & 5-O-Caffeolyquinic acid & $1.46 \pm 0.06$ & $1.07 \pm 0.01$ & $0.87 \pm 0.02$ \\
\hline 4 & 11.02 & 336 & 593 & $473(24), 383(9), 297(24), 253(3)$ & Apigenin 6,8-di-C-glucoside & $1.57 \pm 0.02$ & $1.43 \pm 0.15$ & nd \\
\hline 5 & 11.61 & 328 & 179 & 135(100), 107(4) & Caffeic acid & $1.82 \pm 0.05$ & $2.20 \pm 0.09$ & $1.84 \pm 0.06$ \\
\hline 6 & 14.02 & 282 & 449 & $287(100)$ & Eriodictyol $O$-hexoside & $0.69 \pm 0.02$ & $0.70 \pm 0.07$ & $\operatorname{tr}$ \\
\hline 7 & 15.51 & 350 & 637 & $461(55), 285(38)$ & Luteolin $O$-diglucuronide & $9.96 \pm 0.08$ & $10.11 \pm 0.70$ & $1.66 \pm 0.13$ \\
\hline 8 & 17.79 & 354 & 463 & $301(100)$ & Quercetin $O$-hexoside & $1.18 \pm 0.10$ & $1.46 \pm 0.25$ & $1.48 \pm 0.13$ \\
\hline 9 & 17.83 & 284 & 449 & $287(100)$ & Eriodictyol $O$-hexoside & $1.39 \pm 0.04$ & $1.79 \pm 0.32$ & $1.85 \pm 0.12$ \\
\hline 10 & 18.77 & 346 & 447 & $285(100)$ & Luteolin $\mathrm{O}$-hexoside & $4.27 \pm 0.13$ & $4.67 \pm 0.32$ & $2.19 \pm 0.09$ \\
\hline 11 & 19.17 & 320 & 521 & $\begin{array}{l}\text { 359(100), 197(21), 179(35), } \\
\text { 161(74), 135(13) }\end{array}$ & Rosmarinic acid glucoside & $3.45 \pm 0.06$ & $3.16 \pm 0.31$ & $3.24 \pm 0.02$ \\
\hline 12 & 20.00 & 352 & 609 & $301(100)$ & Quercetin 3-O-rutinoside & $1.31 \pm 0.10$ & $1.46 \pm 0.13$ & $0.75 \pm 0.04$ \\
\hline 13 & 20.55 & 350 & 463 & $301(100)$ & Quercetin 3-O-glucoside & $1.01 \pm 0.06$ & $1.12 \pm 0.04$ & $0.82 \pm 0.01$ \\
\hline 14 & 20.97 & 348 & 461 & $285(100)$ & Luteolin 7-O-glucuronide & $26.59 \pm 0.06$ & $25.63 \pm 0.18$ & $8.79 \pm 0.22$ \\
\hline 15 & 21.03 & 346 & 447 & $285(100)$ & Luteolin 7-O-glucoside & $14.95 \pm 0.30$ & $16.62 \pm 0.58$ & $26.43 \pm 0.30$ \\
\hline 16 & 22.37 & 352 & 477 & $315(100)$ & Isorhamnetin O-hexoside & $0.56 \pm 0.06$ & $0.74 \pm 0.06$ & $0.32 \pm 0.00$ \\
\hline 17 & 23.19 & 284 & 609 & $301(100)$ & Hesperetin 7-O-rutinoside & $4.40 \pm 0.02$ & $7.43 \pm 0.06$ & $4.92 \pm 0.19$ \\
\hline 18 & 24.33 & 330 & 359 & 197(99), 179(90), 161(100), 135(53) & Rosmarinic acid & $23.52 \pm 0.09$ & $23.98 \pm 0.09$ & $22.26 \pm 0.53$ \\
\hline 19 & 25.46 & 340 & 445 & $269(100)$ & Apigenin $\mathrm{O}$-glucuronide & $3.04 \pm 0.29$ & $3.12 \pm 0.09$ & $1.64 \pm 0.13$ \\
\hline 20 & 26.17 & 336 & 607 & 299(100), 284(35) & Methyl kaempferol O-rutinoside & $1.58 \pm 0.05$ & $1.66 \pm 0.11$ & $1.46 \pm 0.07$ \\
\hline 21 & 27.25 & 344 & 461 & $285(100)$ & Kaempferol $O$-glucuronide & $1.91 \pm 0.15$ & $2.10 \pm 0.07$ & $1.15 \pm 0.01$ \\
\hline 22 & 28.46 & 328 & 537 & $\begin{array}{l}\text { 493(100), 359(89), 313(17), 295(64), } \\
\text { 197(27), 179(54), 161(82), 135(82) }\end{array}$ & Lithospermic acid A & nd & $2.64 \pm 0.61$ & $4.38 \pm 0.11$ \\
\hline 23 & 31.02 & 288 & 287 & 151(100), 135(95) & Eriodictyol & $0.11 \pm 0.01$ & $0.11 \pm 0.02$ & $0.66 \pm 0.15$ \\
\hline \multirow[t]{4}{*}{24} & 32.48 & 336 & 283 & $268(100)$ & Methyl apigenin & $0.36 \pm 0.01$ & $0.65 \pm 0.03$ & $0.50 \pm 0.02$ \\
\hline & & & & & Total phenolic acids & $32.69 \pm 0.14^{\mathrm{c}}$ & $35.81 \pm 1.13^{\mathrm{a}}$ & $34.92 \pm 0.69^{\mathrm{b}}$ \\
\hline & & & & & Total flavonoids & $74.87 \pm 1.22^{\mathrm{b}}$ & $80.79 \pm 2.81^{\mathrm{a}}$ & $54.60 \pm 1.00^{\mathrm{c}}$ \\
\hline & & & & & Total phenolic compounds & $107.56 \pm 1.08^{\mathrm{b}}$ & $116.60 \pm 3.95^{\mathrm{a}}$ & $88.59 \pm 1.69^{c}$ \\
\hline
\end{tabular}

In the last three rows different letters mean significant differences $(p<0.05)$. 
From the twenty-four phenolic compounds identified, rosmarinic acid (in all the preparations), luteolin 7-O-glucoside (in the hydroalcoholic extract) and luteolin 7-O-glucuronide (in the infusion and decoction) were the most abundant phenolic acids and flavonoids found. Decoction presented the highest concentration of phenolic compounds (phenolic acids and flavonoids) followed by infusion and hydroalcoholic extract. This can also be related to the highest antioxidant (RSA and RP assays) and antibacterial activity obtained in decoction preparation. There are various publications reporting the phenolic composition of $T$. vulgaris from different origins and obtained by different extraction methodologies (Berdowska et al., 2013; Boros et al., 2010; Dapkevicius et al., 2002; Hossain et al., 2010; Koşar et al., 2005; Kulisic, DragoviUzelac, \& Milos, 2006; Miron et al., 2011; Nagy et al., 2011; Proestos, Chorianopoulos, Nychas, \& Komaitis, 2005; Roby et al., 2013; Vergara-Salinas et al., 2012; Zheng \& Wang, 2001), although the phenolic profiles reported are different in each case, presenting only similarities in some of the compounds identified in our study.

Zheng and Wang (2001) and Berdowska et al. (2013) studied a sample of $T$. vulgaris from the USA and Poland, after extraction with acetone and water (boiling water and further hydrolysis), respectively. Both identified caffeic and rosmarinic acids; these compounds were also identified under this study and rosmarinic acid was also the most abundant phenolic compound detected. They also detected some flavonoids, such as hispidulin, luteolin, luteolin 7-O-glucuronide; the last one was also identified in the present study. Vergara-Salinas et al. (2012) presented the phenolic composition of $T$. vulgaris from Chile obtained after pressurised hot water extraction. These authors identified seventeen compounds (five phenolic acids and twelve flavonoids), seven of which were also detected in the studied samples. Proestos et al. (2005) analysed a sample of $T$. vulgaris from Greece, using aqueous methanol extract with a further hydrolysis of the extract. These authors identified and quantified five phenolic acids (gentisic, caffeic, $p$-coumaric, syringic and $p$-hydroxybenzoic acids) and three flavonoids (apigenin, luteolin and epicatechin). These authors did not identify rosmarinic acid which is the major phenolic acid found in the studied T. vulgaris. Furthermore, Koşar et al. (2005) identified four flavonoids (luteolin glucuronide, eriodictyol, luteolin and apigenin) and one phenolic acid (rosmarinic acid), in a methanolic extract of T. vulgaris from Finland. Rosmarinic acid was the most abundant phenolic compound found. Roby et al. (2013) and Kulisic et al. (2006) studied T. vulgaris samples from Egypt (methanolic extract) and Croatia (infusion preparation), respectively. In the methanolic extract of $T$. vulgaris, eight phenolic acids were identified, being cinnamic acid, a phenolic acid related compound, the major molecule found. These authors also identified five flavonoids, in which the aglycone apigenin was the most abundant. Kulisic et al. (2006) showed results for the infusion of T. vulgaris, identifying three phenolic acids and six flavonoids, and in accordance to the results presented herein, rosmarinic acid was the most abundant compound found. Coincidences with the phenolic compounds detected by other authors (i.e., Boros et al., 2010; Dapkevicius et al., 2002; Hossain et al., 2010; Miron et al., 2011; Nagy et al., 2011) are discussed above in this paper.

The variations observed in the phenolic profiles of samples from different origins could be explained by growing conditions (soil, climate, rainfall, altitude), harvesting, processing, among others, which directly interfere with the content of chemical constituents (e.g., phenolic compounds) and, consequently, in their therapeutic effects (Naghdi Badi, Yazdani, Ali, \& Nazari, 2004).

In summary, the use of infusion and decoction of thyme (rich in phenolic compounds, either phenolic acids or flavonoids), as complementary of daily food, could provide considerable benefits for health, not only in the treatment of diseases related to reactive species production and oxidative stress, but also against bacterial infections. These benefits conferred by thyme can be achieved by both internal and external use and, at the recommended doses, it is safe and no adverse reactions have been described. Nevertheless, further experiments are required in order to explore the mechanisms of action involved.

\section{Acknowledgements}

The authors are grateful to Foundation for Science and Technology (FCT, Portugal) for N. Martins grant (SFRH/BD/87658/2012), L. Barros researcher contract under "Programa Compromisso com Ciência - 2008" and financial support to the research center CIMO (strategic project PEst-OE/AGR/UI0690/2011).

\section{References}

Abdul, B. A., Hassan, A. M., \& Hassan, A. S. (2012). In vitro antimicrobial activity of Thymus vulgaris, Origanum vulgare and Rosmarinus officinalis against dental caries pathogens. Haitham Journal for Pure and Applied Science, 25, 1-7.

Al-Bayati, F. A. (2008). Synergistic antibacterial activity between Thymus vulgaris and Pimpinella anisum essential oils and methanol extracts. Journal of Ethnopharmacology, 116, 403-406.

Barros, L., Pereira, E., Calhelha, R. C., Dueñas, M., Carvalho, A. M., Santos-Buelga, C. et al. (2013). Bioactivity and chemical characterization in hydrophilic and lipophilic compounds of Chenopodium ambrosioides L. Journal of Functional Foods, 5, 1732-1740.

Berdowska, I., Zielinski, B., Fecka, I., Kulbacka, J., Saczko, J., \& Gamian, A. (2013). Cytotoxic impact of phenolics from Lamiaceae species on human breast cancer cells. Food Chemistry, 141, 1313-1321.

Boros, B., Jakabová, S., Dörnyei, A., Horváth, G., Pluhár, Z., Kilár, F., et al. (2010). Determination of polyphenolic compounds by liquid chromatography-mass spectrometry in Thymus species. Journal of Chromatography A, 1217, 7972-7980.

Carocho, M., \& Ferreira, I. C. F. R. (2013). A review on antioxidants, prooxidants and related controversy: Natural and synthetic compounds, screening and analysis methodologies and future perspectives. Food and Chemical Toxicology, 51, $15-25$.

Chahdoura, H., Barreira, J. C. M., Barros, L., Santos-Buelga, C., Ferreira, I. C. F. R., \& Achour, L. (2014). Phytochemical characterization and antioxidant activity of Opuntia microdasys (Lehm.) Pfeiff flowers in different stages of maturity. Journal of Functional Foods, 9, 27-37.

Chaturvedi, R. K., \& Beal, M. F. (2013). Mitochondrial diseases of the brain. Free Radical Biology E' Medicine, 63, 1-29.

Dababneh, B. F. (2007). Antimicrobial activity and genetic diversity of Thymus species on pathogenic microorganisms. Journal of Food, Agriculture \& Environment, 5, 158-162.

Dapkevicius, A., van Beek, T. A., Lelyveld, G. P., van Veldhuizen, A., de Groot, A. Linssen, J. P. H., et al. (2002). Isolation and structure elucidation of radical scavengers from Thymus vulgaris leaves. Journal of Natural Products, 65 $892-896$.

de Carretto, C. F. P., de Navas, E. A. F. A., Paradella, T. C., de Oliveira, L. D., Junqueira, J. C., \& Jorge, A. O. C. (2007). Effects of the thyme infusion on the in vitro adherence of Streptococcus mutans to tooth and Candida albicans to the acrylic resin. Journal of Oncology of UNESP, 36, 281-286.

Giordani, R., Regli, P., Kaloustian, J., Mikaïl, C., Abou, L., \& Portugal, H. (2004) Antifungal effect of various essential oils against Candida albicans. Potentiation of antifungal action of amphotericin B by essential oil from Thymus vulgaris. Phytotherapy Research, 18, 990-995.

Hossain, M. B., Rai, D. K., Brunton, N. P., Martin-Diana, A. B., \& Barry-ryan, C. (2010) Characterization of phenolic composition in Lamiaceae spices by LC-ESI-MS/MS Journal of Agricultural and Food Chemistry, 58, 10576-10581.

Imelouane, B., Amhamdi, H., Wathelet, J. P., Ankit, M., Khedid, K., \& El Bachiri, A. (2009). Chemical composition and antimicrobial activity of essential oil of thyme (Thymus vulgaris) from Eastern Morocco. International Journal of Agriculture E' Biology, 11, 205-208.

Kon, K., \& Rai, M. (2012). Antibacterial activity of Thymus vulgaris essential oil alone and in combination with other essential oils. Bioscience, 4, 50-56.

Kosar, M., Dorman, H. J. D. \& Hiltunen, R. (2005). Effect of an acid treatment on the phytochemical and antioxidant characteristics of extracts from selected Lamiaceae species. Food Chemistry, 91, 525-533.

Kulisic, T., Dragovic-Uzelac, V., \& Milos, M. (2006). Antioxidant activity of aqueous tea infusions prepared from oregano, thyme and wild thyme. Food Technology and Biotechnology, 44, 485-492.

Kulisic, T., Radonic, A., \& Milos, M. (2005). Antioxidant properties of thyme (Thymus vulgaris L.) and wild thyme (Thymus serpyllus L.) essential oils. Italian Journal of Food Science, 17, 315-325.

Maroyi, A. (2013). Traditional use of medicinal plants in south-central Zimbabwe: Review and perspectives. Journal of Ethnobiology and Ethnomedicine, 9, 1-18.

Miron, T. L., Plaza, M., Bahrim, G., Ibáñez, E., \& Herrero, M. (2011). Chemical composition of bioactive pressurized extracts of Romanian aromatic plants. Journal of Chromatography A, 1218, 4918-4927. 
Naghdi Badi, H., Yazdani, D., Ali, S. M., \& Nazari, F. (2004). Effects of spacing and harvesting time on herbage yield and quality/quantity of oil in thyme, Thymus vulgaris L. Industrial Crops and Products, 19, 231-236.

Nagy, T. O., Solar, S., Sontag, G., \& Koenig, J. (2011). Identification of phenolic components in dried spices and influence of irradiation. Food Chemistry, 128, 530-534.

NCCLS/CLSI, \& ANVISA. (2003). Standardization of the antimicrobial susceptibility tests for disc-diffusion: Approved Standard - Eighth Edition.

Oussalah, M., Caillet, S., Saucier, L., \& Lacroix, M. (2007). Inhibitory effects of selected plant essential oils on the growth of four pathogenic bacteria: E. coli 0157:H7, Salmonella typhimurium, Staphylococcus aureus and Listeria monocytogenes. Food Control, 18, 414-420.

Proestos, C., Chorianopoulos Nychas, G.-J. E., \& Komaitis, M. (2005). RP-HPLC analysis of the phenolic compounds of plant extracts. Investigation of their antioxidant capacity and antimicrobial activity. Journal of Agricultural and Food Chemistry, 53, 1190-1195.

Roby, M. H. H., Sarhan, M. A., Selim, K. A.-H., \& Khalel, K. I. (2013). Evaluation of antioxidant activity, total phenols and phenolic compounds in thyme (Thymus vulgaris L.), sage (Salvia officinalis L.), and marjoram (Origanum majorana L.) extracts. Industrial Crops and Products, 43, 827-831.

Ruan, M., Li, Y., Li, X., Luo, J., \& Kong, L. (2012). Qualitative and quantitative analysis of the major constituents in Chinese medicinal preparation Guan-Xin-Ning injection by HPLC-DAD-ESI-MSn. Journal of Pharmaceutical and Biomedical Analysis, 59, 184-189.

Rubió, L., Motilva, M.-J., \& Romero, M.-P. (2013). Recent advances in biologically active compounds in herbs and spices: A review of the most effective antioxidant and anti-inflammatory active principles. Critical Reviews in Food Science and Nutrition, 53, 943-953.
Silva, N. C. C., \& Fernandes Júnior, A. (2010). Biological properties of medicinal plants: A review of their antimicrobial activity. The Journal of Venomous Animals and Toxins including Tropical Diseases, 16, 402-413.

Vallverdú-Queralt, A., Regueiro, J., Martínez-Huélamo, M., Alvarenga, J. F. R., Leal, L. N., \& Lamuela-Raventos, R. M. (2014). A comprehensive study on the phenolic profile of widely used culinary herbs and spices: Rosemary, thyme, oregano, cinnamon, cumin and bay. Food Chemistry, 154, 299-307.

Van Vuuren, S. F., Suliman, S., \& Viljoen, A. M. (2009). The antimicrobial activity of four commercial essential oils in combination with conventional antimicrobials. Letters in Applied Microbiology, 48, 440-446.

Vanaclocha, B., \& Cañigueral, S. (2003). Fitoterapia: Vademecum de Prescripción. (Masson, Ed.) (4th ed., p. 1092). Barcelona.

Vergara-Salinas, J. R., Pérez-Jiménez, J., Torres, J. L., Agosin, E., \& Pérez-Correa, J. R. (2012). Effects of temperature and time on polyphenolic content and antioxidant activity in the pressurized hot water extraction of deodorized thyme (Thymus vulgaris). Journal of Agricultural and Food Chemistry, 60, 10920-10929.

Viuda-Martos, M., Navajas, Y. R., Zapata, E. S., Fernández-López, J., \& Pérez-Álvarez, J. A. (2010). Antioxidant activity of essential oils of five spice plants widely used in a Mediterranean diet. Flavour and Fragrance Journal, 25, 13-19.

Viuda-Martos, M., Ruíz-Navajas, Y., Fernández-López, J., \& Pérez-Álvarez, J. A. (2007). Chemical composition of the essential oils obtained from some spices widely used in Mediterranean region. Acta Chimica Slovenica, 54, 921-926.

Zeng, G., Xiao, H., Liu, J., \& Liang, X. (2006). Identification of phenolic constituents in Radix Salvia miltiorrhizae by liquid chromatography/electrospray ionization mass spectrometry Rapid Communications in Mass Spectrometry, 20, 499-506.

Zheng, W., \& Wang, S. Y. (2001). Antioxidant activity and phenolic compounds in selected herbs. Journal of Agricultural and Food Chemistry, 49, 5165-5517. 